\title{
Efficiency of Microalgae Scenedesmus in the Removal of Nitrogen from Municipal Wastewaters
}

\author{
Fatemeh Amini Fard 1(D), Reza Jalilzadeh Yengejeh*1(iD), Mansoureh Ghaeni ${ }^{2}$ id
}

${ }^{1}$ Department of Environmental Engineering, Ahvaz Branch, Islamic Azad University, Ahvaz, Iran.

${ }^{2}$ Department of Fisheries, Ahvaz Branch, Islamic Azad University, Ahvaz, Iran.

\begin{tabular}{ll}
\hline Article Info & A B S T R A C T \\
\hline $\begin{array}{l}\text { Article type: } \\
\text { Original Article }\end{array}$ & Background: \\
\hline Article History: & Due to the high content of nitrogen in the municipal wastewaters, this study \\
Received: $2019-02-23$ & evaluated the efficiency of Scenedesmus as an important microalgae in the \\
Accepted: $2019-04-17$ & removal of nitrate from wastewaters and its application as an appropriate \\
& culture medium. As algae have high resistance to temperature and pH changes, \\
& they can absorb low concentrations of nutrients and need simple low-cost \\
& technology. Through photosynthesis, microalgae effectively stabilize carbon \\
${ }^{*}$ Corresponding author: & dioxide at a low cost, and the oxygen produced by the photosynthesis process \\
Reza Jalilzadeh Yengejeh & can reduce the biochemical oxygen demand (BOD) of wastewaters.
\end{tabular}

Reza Jalilzadeh Yengejeh

Department of Environmental

Engineering, Ahvaz Branch, Islamic

Azad University, Ahvaz, Iran.

E-mail: r.jalilzadeh@iauahvaz.ac.ir

\section{Methods:}

In this research, the chemical oxygen demand (COD), BOD, $\mathrm{pH}$, total nitrogen (TN), and microalgae density were measured in the samples within 14 days after sampling from the inlet and outlet of municipal wastewaters treatment plant.

Results:

The results showed that nitrogen removal rate from the wastewaters at the laboratory conditions was $93 \%$ in the inlet and $85 \%$ in the outlet, which are higher in efficiency than those provided by other treatment processes.

\section{Conclusion:}

The microalgae can be used for the removal of nitrate and the production of algae biomass in municipal wastewaters processes before entering the natural environment.

Keywords:

Microalgae; Municipal Wastewaters; Nitrogen; Nutrients.

How to cite this paper

Amini Fard F, Jalilzadeh Yengejeh R, Ghaeni M. Efficiency of Microalgae Scenedesmus in the Removal of Nitrogen from Municipal Wastewaters. Iran J Toxicol. 2019; (2):1-6

\section{INTRODUCTION}

The discharge of municipal and industrial wastewaters into the environment has caused hazardous impacts due to the organic and toxic contaminants $(\underline{1,2})$. Nitrate and nitrite are part of the environmental nitrogen cycle ( $\underline{3})$. The nitrogen-bearing compounds have detrimental effects on the aqueous environment. These effects include ammonia toxicity, high growth of aquatic plants, contamination of groundwaters with nitrates, and diseases caused by the consumption of nitrate-contaminated waters $(\underline{1,2,4})$. The high concentration of nitrogen in aqueous environments also causes premature aging (eutrophication phenomenon), which is associated with the deterioration of water quality and loss of aquatic organisms $(\underline{5,6})$. Microalgae is a class of plants wastewaters $(\underline{10})$. The application of microalgae for wastewaters treatment offers several advantages to the distributed widely in both terrestrial and marine environments. More than 40 different species of microalgae have been studied for multiple purposes, such as fresh water environmental protection, biomass production and content analysis. Microalgae can absorb various forms of nitrogen and heavy metals. Nutritional deficiencies or excesses can have detrimental effect on the growth of algae and the efficacy in their nutrient uptake. As the levels of nutrients are not controlled at the outlet of wastewaters treatment plants, it is necessary to use new methods to remove organic materials ( $\underline{7-9})$. Nutrient-rich environments are considered suitable sources for the proliferation of microalgae.

Various microalgae, such as Scenedesmus, Chlorella have been used to treat municipal and industrial ecosystem, such as the elimination of environmental contaminants, absence of secondary contaminants, and the ability of microalgae to effectively recirculate 
nutrients found in the secondary wastewaters (11-13). In a study (14), the microalgae Scenedesmus was used to remove nitrogen and the chemical oxygen demand from soft drink and alcohol wastewater. The authors investigated the cell physiology and enzyme activity during the wastewaters treatment. All of the batches and continuous reactors showed that the cells had a density of more than $87 \%$ in the membrane, although relatively small continuous cultures of cells' enzymatic activity (20-40\%) were shown compared to those in batch cultures (97\%) (14). In another study, microalgae were cultivated in controlled media to simulate the synthetic wastewater and the single-stage culture systems. The study showed a production rate of $132.8 \mathrm{mg} /$ day for biomass $(\underline{15})$.

The objectives of this study, are as follows: (a) measuring the removal rate of organic and nutrient materials in the municpal wastewaters in western Ahvaz; (b) determination of the chemical oxygen demand (COD) at the inlet and outlet of the municipal wastewaters treatment plant and industrial wastewaters samples, using freshwater microalgae (Scenedesmus), and (c) determination of microalgae population and density of freshwater microalgae (Scenedesmus).

\section{MATERIALS AND METHODS}

Microalgae: The general conditions for the cultivation of microalgae are based on the Laven method (16). We used wastewaters samples and stocks collected from the Iranian Fisheries Science Research Institute (Tehran, Iran).

\section{Preparation of Required Materials and Pilot}

Setup: The required pilot study was designed and conducted as illustrated in Figure 1. A 2L Erlenmeyer flask was used for both the experiments and pilot studies. Three aquarium pumps were also used to maintain aerobic conditions. Two fluorescent lamps were used to supply the required lighting. All stages of work and tests were carried out in the laboratory conditions at an ambient temperature of $25^{\circ} \mathrm{C}$.

Wastewaters Sampling: The sampling was carried out in three steps (April 2018) from two stations in the inlet and outlet of the western Ahvaz wastewaters treatment plant, using 20L containers through the inoculation of the cultured microalgae for specified volumes. The physicochemical parameters and variables were determined before the actual tests. After ensuring that the alga samples were pure, four $2 \mathrm{~L}$ Erlenmeyer flask were used to collect water samples from the inlet and outlet, and two 1L flasks were assigned to the control samples.

The chemical parameters and the desired variables of the study were assessed prior to the actual experiments. By performing the tests and determining the variables from both the pilot input and output stations, the efficiency of removing the variables was determined. Lastly, we compared the removal of some of the parameters for the treatment plant. Of note, the salinity of the wastewaters samples was increased to $15 \mathrm{~g} / \mathrm{L}$ in order to create optimal growth conditions for the microalgae.

Experiments: The experimental media were kept in six Erlenmeyer flasks $(200 \mathrm{ml})$; three for the inlet and another three for the outlet wastewaters. Each flask contained 20cc purified stock of microalgae Scenedesmus, inoculated under laboratory conditions. Aeration was carried out continuously ( $24 \mathrm{hr}$ ), using an aquarium pump, with the air hose placed inside a micropipette in each flask. The samples were exposed to controlled illumination $24 \mathrm{hr}$ a day at $25^{\circ} \mathrm{C}$, using two fluorescent lamps. The efficiency of removing the variables from the media was determined for the pilot inlet and oulet samples. In order to create optimal conditions for the microalgae, the salinity of wastewaters samples was set at $15 \mathrm{~g} / \mathrm{L}$ (Figures 1a \& 1b).

Study Parameters: In this study, the BOD, COD, $\mathrm{pH}$, temperature, $\mathrm{TN}$, temperature, algae, and microbial cell density parameters were measured in the inlet and outlet samples. The test time was 14 days and some parameters (such as salinity, temperature, cell density, $\mathrm{pH}$ ) were measured daily. Also, other parameters, such as BOD, COD, TN and temperature were measured periodically.

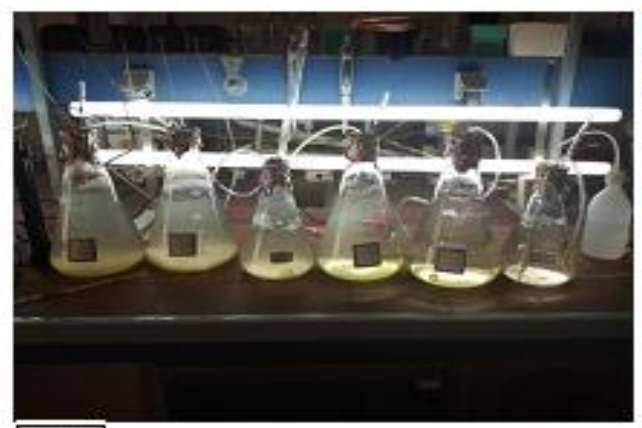

[a]

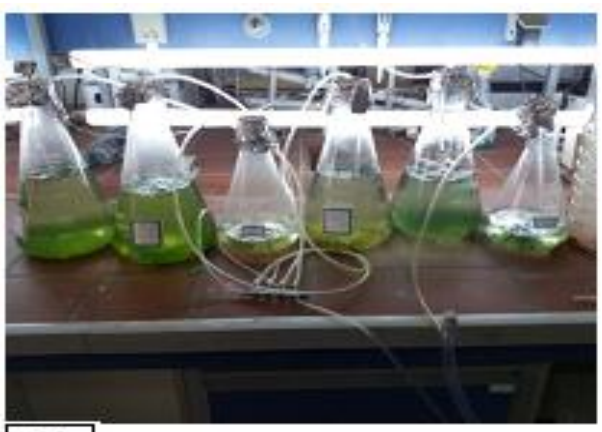

(b)

Figure 1. (a): First day of microalgae Scenedesmus growth in wastewater treatment plant. (b): $14^{\text {th }}$ day of microalgae Scenedesmus growth in wastewaters treatment plant outlet. 


\section{RESULTS}

\section{Performance of Municipal Wastewaters}

Treatment Plant: The characteristics of the wastewaters treatment plant are listed in Tables 1 and 2. The quantities of the parameters, nitrogen and contamination indices (BOD \& COD) were within the standard range. The performance of the treatment plant was suitable for the removal of the parameters at the time of measurement (July 2018), within the standard range of discharge to surface waters.

\section{Results for Removal of Nutrients from Wastewaters Influent by Microalgae} Scenedesmus: The diagrams of the average nitrogen change in the wastewaters inlet and outlet, in the presence of microalgae Scenedesmus, are shown in Figures 4 and 5. This experiment was conducted randomly in duplicate at two treatment stations within 14 days. As shown in Figure 2 (a,b), the variation in wastewaters inlet in the presence of Scenedesmus decreased starting on the fifth to the tenth day of the experiment. The $\mathrm{R}^{2}$ value was 95 , indicative of good correlation among the data, based on simple linear regression. As shown in Figure $3(\mathrm{a}, \mathrm{b})$, the variation in the samples taken from the wastewaters outlet in the presence of the microalgae Scenedesmus decreased up to the eleventh day followed by a steady trend. The total nitrogen content at the beginning of experiments was $30 \mathrm{mg} / \mathrm{L}$, but it decreased to $4.45 \mathrm{mg} / \mathrm{L}$, indicating an $83 \%$ efficiency rate. However, there was no significant changes in the $\mathrm{pH}$ and electrical conductivity
(EC) values (Figures $4 \& 5$ ). The BOD values at the inlet and outlet showed a decline of $92 \%$ and $13 \%$, respectively, with the rate of COD removal being $74 \%$ during the sampling.

Based the mesearment of other effective parameters, the $\mathrm{pH}$ variations were very small, ranging from 8.4 at the start to 9.2 at the end of the experiments. The $\mathrm{pH}$ variations in the outlet samples were much lower than those of the inlet samples. Also, changes in the electrical conductivity of both the inlet and outlet samples were very small. A comparison of the removal rate of BOD at the inlet and outlet in the presence of Scenedesmus is shown in Figure 5. The efficiency of Scenedesmus in the removal of BOD from the samples collected at the inlet and outlet were 92\% and 13\%, respectively. The significant difference was caused by the presence of high nutrients at the inlet. However, the indicator at the outlet was $22 \mathrm{mg} / \mathrm{L}$; Scenedesmus was able to reduce this value to to $22 \%$ and ultimately to $19.2 \%$.

The removal efficiency of nutrients by Scenedesmus at the inlet and outlet are compared in Figure 6. The algae had a greater ability to remove nitrate than that achieved by the treatment plant, using conventional activated sludge. The removal rate of COD in the inlet samples was $74 \%$. Figure 7 shows the growth rate of microalgae, representing the variations in the tested water samples. The growth rate increased until the ninth day, then followed a declining trend.

Table 1. Characteristics of study treatment plant.

\begin{tabular}{lllll}
\hline Parameter & $\begin{array}{l}\text { Average } \\
\text { inlet }\end{array}$ & $\begin{array}{l}\text { Average } \\
\text { outlet }\end{array}$ & $\begin{array}{l}\text { Standard outlet to } \\
\text { surface water }\end{array}$ & $\begin{array}{l}\text { Treatment } \\
\text { efficiency }\end{array}$ \\
\hline $\mathrm{TN}(\mathrm{mg} / \mathrm{L})$ & 57 & 30 & 50 (nitrate) & $47 \%$ \\
\hline
\end{tabular}

Table 2. Performance of municipal wastewaters treatment plant.

\begin{tabular}{lllll}
\hline Parameter & Average inlet & Average outlet & $\begin{array}{l}\text { Standard outlet to } \\
\text { surface water }\end{array}$ & $\begin{array}{l}\text { Treatment } \\
\text { efficiency }\end{array}$ \\
\hline BOD $(\mathrm{mg} / \mathrm{L})$ & 290 & 25 & 30 & $91 \%$ \\
COD $(\mathrm{mg} / \mathrm{L})$ & 450 & 52 & 60 & $88 \%$ \\
pH & 8 & 8.21 & $6.5-8.5$ & - \\
Temperature $\left({ }^{\circ} \mathrm{C}\right)$ & 26 & 25 & Note 4 & - \\
TN $(\mathrm{mg} / \mathrm{L})$ & 57 & 30 & 50 (nitrate) & $47 \%$ \\
\hline
\end{tabular}

Key: $\mathrm{BOD}=$ Biochemical oxygen demand; $\mathrm{COD}=$ Chemical oxygen demand; $\mathrm{TN}=$ Total nitrogen .
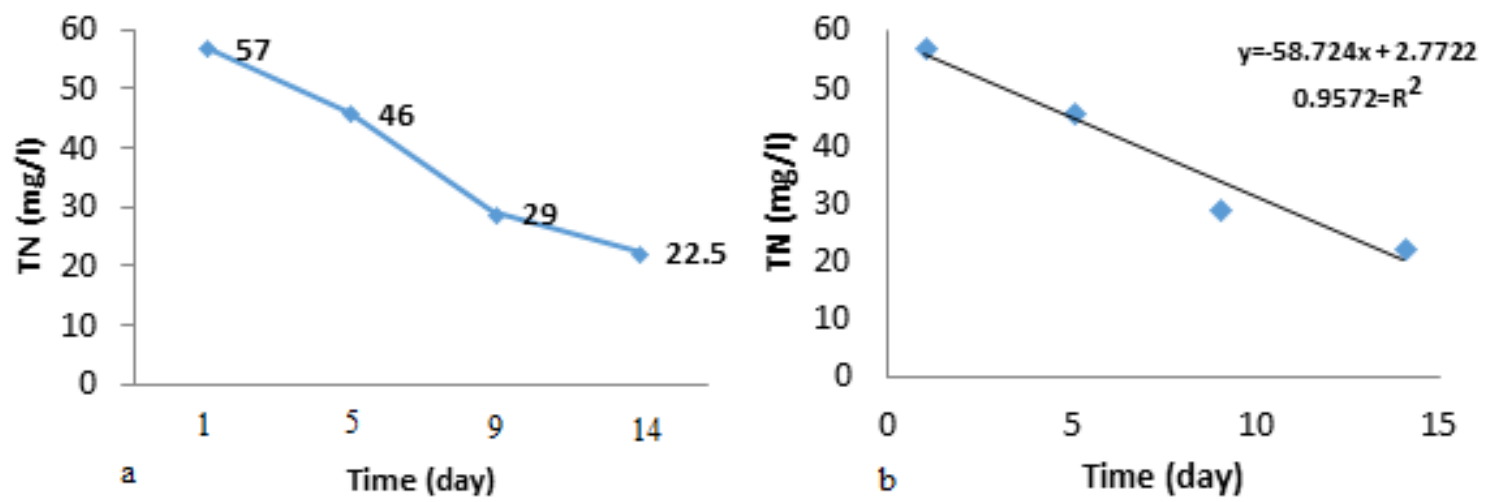

Figure 2. (a) - Average total nitrogen (TN) changes in wastewaters influent in presence of microalgae Scenedesmus. (b) - Linear regression diagram of average total nitrogen (TN) changes in wastewaters effluent in presence of microalgae Scenedesmus. 


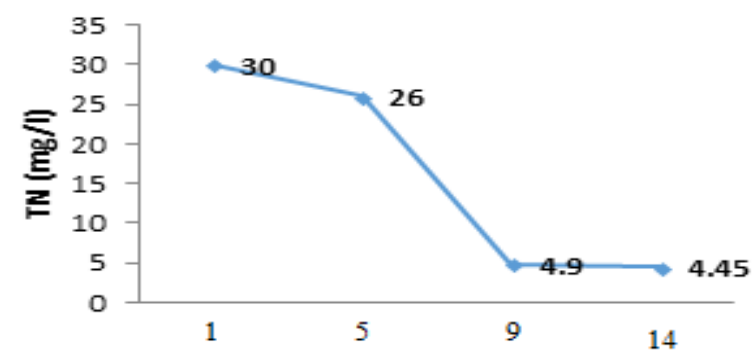

a.

Time (day)

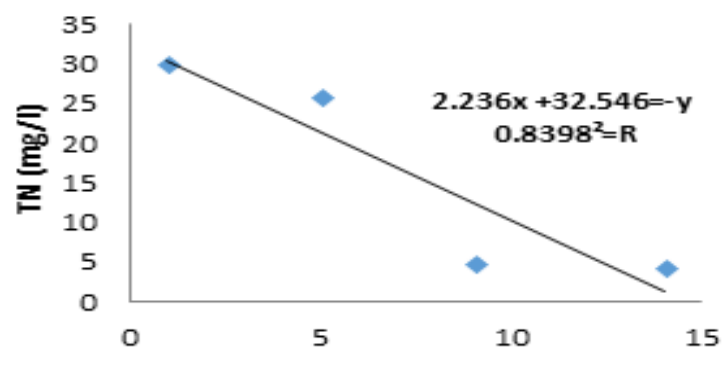

$\mathrm{b}$

Time (day)

Figure 3. (a) - Average total nitrogen (TN) changes in wastewaters effluent in presence of microalgae Scenedesmus. (b) - Linear regression diagram of average nitrogen (TN) changes in wastewaters effluent in presence of microalgae Scenedesmus.

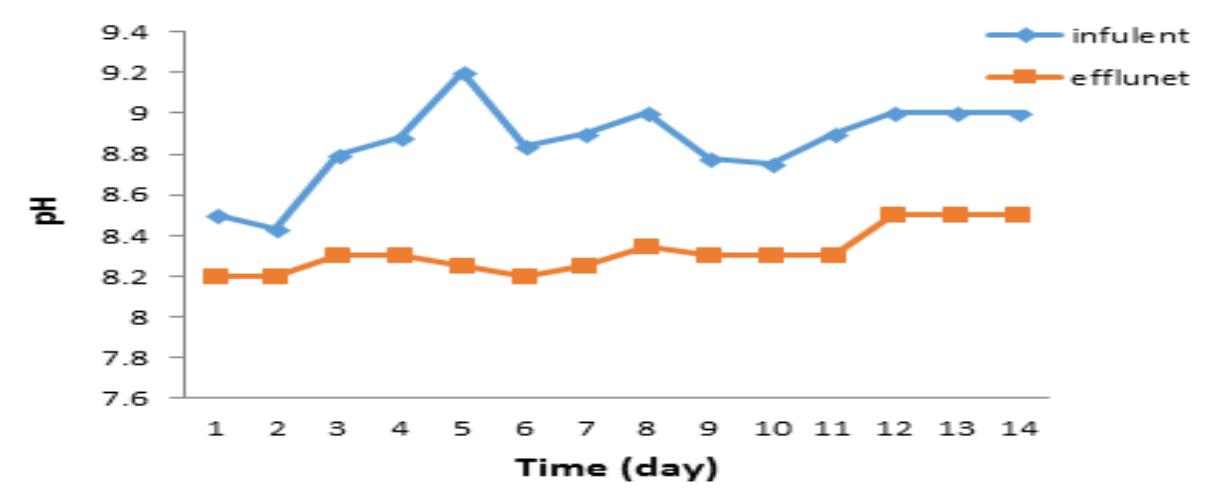

Figure 4. The $\mathrm{pH}$ changes in influent/effluent samples with the microalgae present.

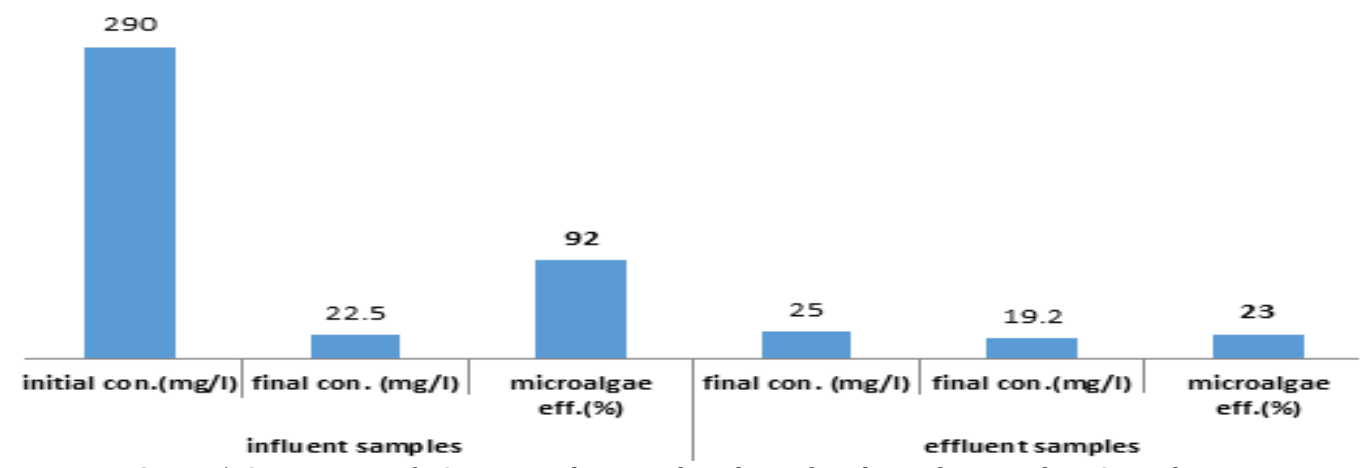

Figure 5. Comparison of BOD removal rate at the inlet and outlet with microalgae Scenedesmus.

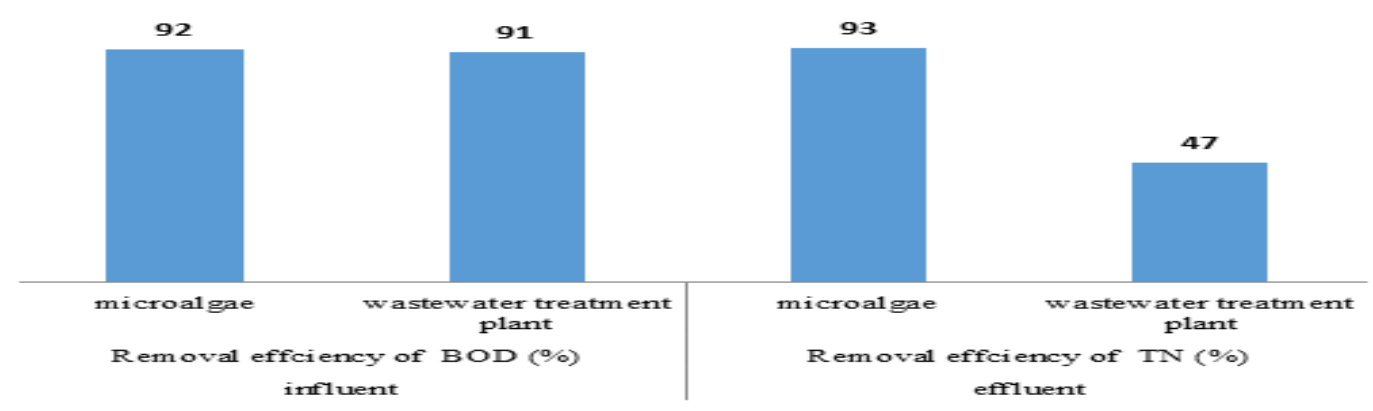

Figure 6. Comparison of nutrients removal at the inlet with microalgae Scenedesmus.

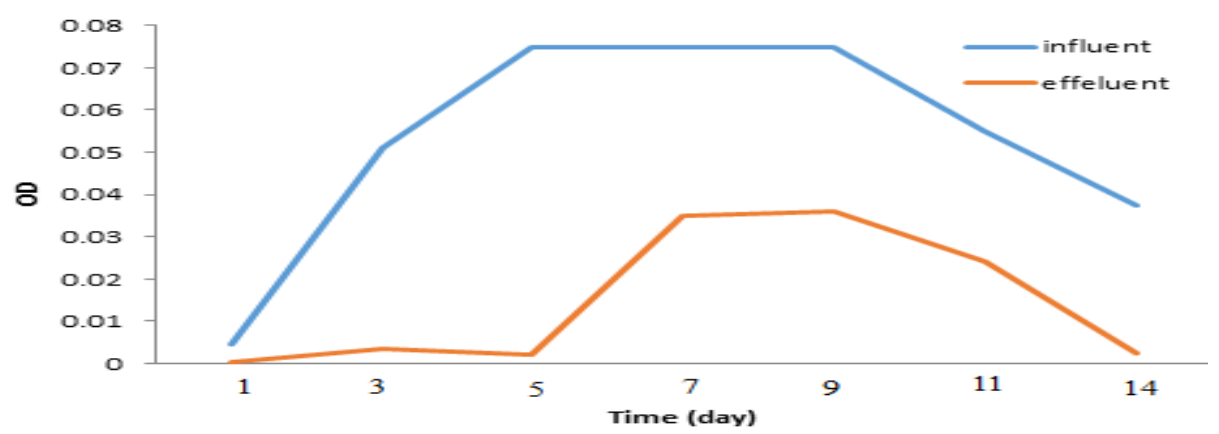

Figure 7. Growth rate of Scenedesmus based on the optical density in the wastewaters at the inlet and outlet in presence of Scenedesmus. 


\section{DISCUSSION}

Numerous studies have been conducted at various laboratories with a focus on the bioremediation of wastewaters, using algae, especially for the removal nitrogen (17-21). This study investigated the efficiency of nutrients removal, using Scenedesmus, from wastewaters collected at the inlet and outlet of the treatment plant at western Ahvaz watewaters treatmen plant. We obtained a 93\% efficiency for nitrogen removal at the inlet. Considering the high nitrogen levels of the inlet samples at the start of the experiment, our results demonstrate an $85 \%$ efficiency for Scenedesmus for removing nitrogen from the wastewaters up until the $9^{\text {th }}$ day of experiments. The increased nitrogen content increases the microalgae growth. The form of nitrogen can also affect the microalgae growth. Generally, NH4- N, NH3- N and NH are useful nutrients for microalgae. However, $\mathrm{NH} 4-\mathrm{N}$ is easier to absorb than NH3-N for microalgae (16). In addition, there was a significant decrease in the outlet samples for the removal of BOD and COD. The growth rate of microalgae and the resistance to nitrogen reduction is largely a function of the environmental conditions in the area where we collected samples. In this context, several studies have been conducted, all of which indicate that the removal of nutrients from the aqueous sources, such as municipal wastewater. Some of these cases are described as follows.

The cultivation of Scenedesmus species in wastewaters has resulted in the complete removal of $\mathrm{NH}_{3}-\mathrm{H}$ in addition to $93 \%$ of total nitrogen and $61 \%$ of orthophosphate (19). A study was conducted in Vietnam to reduce the pollution caused by wastewaters at a large commercial center (20), where the nitrogen removal rate at the inlet was $93 \%$. Another study used microalgae and microbial consortium to remove nitrogen and harmful nutrients from wastewaters at different $\mathrm{pH}$ and lighting conditions $(\underline{21})$. Based on the findings of this study, a new treatment plant is being developed in Ahvaz to minimize the nitrogen content in the outlets of wastewaters.

\section{CONCLUSION}

The efficiency of removing nitrogen from the municipal wastewaters at western Ahvaz treatment plant suggests the ability of this valuable microalgae for the treatment of wastewaters here and elsewhere in Iran. The process of wastewaters treatment and the potential of algae species indicate that the nitrogenrich wastewaters and the light sources provides suitable environments for the proliferation of algae to be used at large scales in the reduction or elimination of nitrogen contamination in municipal wastewaters. Our findings provide evidence that microalgae Scenedesmus can play an effective role in the treatment of wastewaters. In addition, our results indicate that major nitrogen reductions of $93 \%$ and $91 \%$ were observed at both the inlet and outlet of the treatment plant, respectively. The main points of our findings are summarized as follows:

Wastewaters have a good potential for growing microalgae due to their nutrient contents. Factors such as the optimal temperature and biomass concentrations influence the microalgae growth in the wastewaters environment.

Microalgae Scenedesmus has a great ability to remove organic materials from wastewaters and can increase the rate of wastewaters treatment by adjusting the temperature and concentration of biomass and other relevant conditions.

The most important limitation in using microalgae to treat wastewaters is its high sensitivity to toxic compounds, pathogens and bacteria. We recommend conducting research on the separation methods of microalgae from the treatment process and use them repeatedly in the treatment of municipal and industrial wastewaters.

\section{ACKNOWLEDGEMENT}

This Article was extracted from the materials of the M.Sc. degree thesis conducted by Miss Fatemeh Amini Fard, under the expert supervision of Dr. Reza Jalilzadeh at the Department of Environmental Engineering, Ahvaz Branch, Islamic Azad University, Ahvaz, Iran.

\section{CONFLICT OF INTEREST}

The authors have no conflict of interest in conducting this study.

\section{REFERENCE}

1. Shahandeh N, JalilzadehYengejeh R. Efficiency of SBR Process with a Six Sequence Aerobic-Anaerobic Cycle for Phosphorus and Organic Material Removal from Municipal Wastewater. Iranian Journal of Toxicology. 2018;12(2):27-32.

2. Khichi SS, Anis A, Ghosh S. Mathematical modeling of light energy flux balance in flat panel photobioreactor for Botryococcus braunii growth, $\mathrm{CO} 2$ biofixation and lipid production under varying light regimes.Biochemical Engineering Journal. 2018;134:44-56.

3. Almasi A, Shokri R, Momenzadeh R, Rezaei S, Jamshidi A, Yazdizadeh R. Distribution of groundwater nitrate in Dehloran, Iran: A case study using GIS. Journal of Advances in Environmental Health Research. 2016;4(3):155-160.

4. Khademi Mohammadi MJ, Shokri R, Takdastan A, Mohammadi M, Momenzadeh R, Yari AR. Application of cane bagasse adsorption on nitrate removal from groundwater sources: Adsorption isotherm and reaction kinetics. Desalin Water Treat. 2018;120:241-247.

5. Almasi A, Mohammadi M, Shokri R, Hashemi M, Bahmani N. Effect of solar light on the decrease of microbial contamination in facultative stabilization pond. Journal of Advances in Environmental Health Research. 2018;6(2):91-96.

6. Babaei AA, Azari A, Kalantary RR, Kakavandi B. Enhanced removal of nitrate from water, using nZVI@ MWCNTs composite: Synthesis, kinetics and mechanism of reduction. Water Science and Technology. 2015;72(11):1988-1999.

7. Kazemi Noredinvand B, Takdastan A, Jalilzadeh Yengejeh R. Removal of organic matter from drinking water by single and dual media filtration: A comparative pilot 
study. Desalination and Water Treatment. 2016;57(44):20792-20799.

8. Jagadevan S, et al. Recent developments in synthetic biology and metabolic engineering in microalgae towards biofuel production. Biotechnology for Biofuels. 2018;11(1):185. Doi.org/10.1186/s13068-018-1181-1

9. Chew KW, Chia SR, Show PL, Yap Y J, Ling T C, Chang JS. Effects of water culture medium, cultivation systems and growth modes for microalgae cultivation: A review. Journal of the Taiwan Institute of Chemical Engineers. 2018;91, 332-344. Doi.org/10.1016/j.jtice.2018.05.039.

10. Shokri R, Derikvand E, Souri A, Mahvi A, Hashemi M. Prediction of H2S Production Rate in Sewer Systems Using the Z Model: A Case Study in Dehloran City, Iran. J Adv Environ Health Res. 2018;6(3):152-159.

11. Vuppaladadiyam AK, Prinsen $P$, Raheem A, Luque R, Zhao M. Microalgae cultivation and metabolites production: A comprehensive review. Biofuels, Bioproducts and Biorefining. 2018;12(2):304-324.

12. Nemade TV. Synthesis of Silver Nanoparticles Using Microalgae in the Multi-Vessel Reactor. M.S. Thesis, May 12, 2018. College of Engineering, Lamar University, Beaumont, Texas.

13. Cameron H, Mata MT, Riquelme C. The effect of heavy metals on the viability of Tetraselmis marina AC16-MESO and an evaluation of the potential use of this microalga in bioremediation. Peer J. 2018 Jul 25;6:e5295. Doi: 10.7717/peerj.5295. eCollection 2018.

14. Mata TM, Martins AA, Caetano NS. Microalgae for biodiesel production and other applications: A review. Renewable and Sustainable Energy Reviews. 2010;14(1):217-232.
15. Romero-Villegas G, Fiamengo M, Fernández FA, Grima EM. Utilization of centrate for the outdoor production of marine microalgae at pilot-scale in flat-panel photobioreactors. J Biotech. 2018;284:102-114.

16. Lavens P, Sorgeloos P. Manual on the Production and Use of Live Food for Aquaculture. Fisheries and Aquaculture Department, Laboratory of Aquaculture and Artemia Reference Center. Chapter 2.3. Algal production. University of Ghent, Ghent, Belgium, 1996.

17. Shi J, Podola B, Melkonian M. Removal of nitrogen and phosphorus from wastewater using microalgae immobilized on twin layers: An experimental study. J Applied Phyco. 2007;19(5):417-423.

18. Kube M, Jefferson B, Fan L, Roddick F. The impact of wastewater characteristics, algal species selection and immobilisation on simultaneous nitrogen and phosphorus removal. Algal Res. 2018;31:478-488.

19. Oliveira GA, Carissimi E, Monje-Ramírez I, VelasquezOrta SB, Rodrigues RT, Ledesma MTO. Comparison between coagulation-flocculation and ozone-flotation for Scenedesmus microalgal biomolecule recovery and nutrient removal from wastewater in a high-rate algal pond. Bioresource Tech. 2018;259:334-342.

20. Ha BM, Huong DTG, Xuyen LTH. Removal of Inorganic Nutrient and Organic Carbon from Wastewater of Binh Dien Market, Using Green Alga Chlorella sp. Geo Science Eng. 2016;62(4):27-31.

21. Jia H, Yuan Q. Removal of nitrogen from wastewater using microalgae and microalgae-bacteria consortia. Cogent Environtal Science. 2016;2(1):1275089. Doi.org/10.1080/23311843.2016.1275089. 